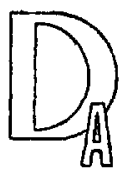

ESTUETOS

\title{
LOS INFORMES ADMINISTRATIVOS COMO ACTOS DE INSTRUCCION DEL PROCEDIMIENTO ADMINISTRATIVO $\left(^{(*)}\left({ }^{* *}\right)\right.$
}

\author{
Por FRANCISCO GONZALEZ NAVARRO
}

$35.077 .7(46)$

Sumario: 1. Introducción. - 2. Concepto, naturaleza, regulación y clases.-3. Procedimiento-4. Efectos.-5. Conclusiones.

\section{Introducción}

$\square_{N}$ el presente trabajo examinamos un aspecto, posiblemente el más importante, de la función consultiva: la ejercida por órganos administrativos. $Y$ este examen lo hacemos, por explicables condicionamientos de nuestra particular dedicación, desde la

(") Este trabajo ha sido escrito para el libro homenaje al profesor doctor Eugenlo Perez BotrJa, con motivo de sus bodas de plata con la cátedra. il publicarlo ahora prescindimos de las notas que sirven de apoyatura o de aclaración, según los casos, a nuestras afirmaciones. Dichas notas serán publicadas, en su dia, con el referido llbro.

(*) Abreviaturas utilizadas:

Cc = Código civil de 24 de julio de 1889.

LEC = Ley de Enjuiciamiento Civil de 3 de febrero de 1881.

LPA $=$ Ley de Procedimiento administrativo de 17 de julio de 1958.

RF = Reglamento de Funcionarios de Administración local de 30 de mayo de 1952.

ROF = Reglamento de Organización, funcionamiento y régimen jurídico de las Corporaciones locales de 17 de mayo de 1952.

RPEA $=$ Reglamento de Procedimiento económico-administrativo de 26 de noviembre de 1959.

STS = Sentencia del Tribunal supremo. 
perspectiva concreta del procedimiento administrativo. Hay, por tanto, una doble limitación inicial en nuestro estudio que comporta una serie de exclusiones, seguramente dolorosas pero inevitables.

Ante todo, quedan fuera de nuestra investigación las cuestiones que ofrece el estudio de la función consultiva realizada por órganos legislativos o jurisdiccionales.

Por otra parte, escapa a nuestra consideración la función ejercida por aquellos órganos administrativos que suelen comprenderse dentro del concepto de staff consultivo general y la desarrollada por muchas modalidades del staff consultivo especializado.

Finalmente, desbordan nuestro campo visual otra serle de informes de órganos administrativos que no se incorporan a un procedimiento administrativo, bien porque tengan una finalidad más de información que de asesoramiento, bien porque deban incidir en un procedimiento jurisdiccional (por ejemplo, los informes sustitutorios de la confesión judicial, previstos en el artículo 595, LEC).

\section{Concepto, naturaleza, regulación y clases}

\subsection{Concepto}

\subsection{Actividad de instrucción y actividad de ordenación}

Por exigencias expositivas derivadas de la misma raíz etimológica de la voz procedimiento suelen los autores separar tres fases o momentos en el procedimiento administrativo: fase de iniciación, fase de desarrollo y fase de terminación.

Al ocuparse de la fase de desarrollo, esos mismos autores distinguen dos tipos de actividades diversas: a) Actividades de instrucción, que tienen por finalidad la aportación y comprobación de los datos que han de servir de base a la resolución, y b) Actividades de ordenación, que van dirigidas precisamente a conseguir el desenvolvimiento del procedimiento.

Esta inclusión de los actos de ordenación dentro de la fase de desarrollo-que se hace en base a una sistemática tomada de la doctrina procesal- no nos parece acertada. Porque «la ordenación, por su propia naturaleza, tiene lugar desde el momento mismo en que se inicia el procedimiento hasta que se termina».

Más exacto resulta separar el estudio de las fases del procedimiento (iniciación, desarrollo o instrucción y terminación) del mecanismo que hace posible el desenvolvimiento de esas fases hasta 
llegar al momento final, es decir, que organiza la serie de actos de que el procedimiento se compone (ordenación).

Por ello consideramos más adecuada la colocación sistemática de la ordenación inmediatamente antes o inmeditamente después del estudio de dichas fases.

Y no está de más anotar que la divergencia sistemática con la que pretendemos romper los tradicionales moldes expositivos aparece reflejada en la regulación que los textos legales vigentes hacen de los actos de ordenación del procedimiento administrativo.

\subsection{Actividad de instrucción $y$ actividad de informe}

Pues bien, en un intento de clasificación de las diversas actividades de desarrollo o instrucción, hemos distinguido alguna vez las actividades de aportación de datos-alegaciones; audiencia, información pública-, las actividades de comprobación de datos - pruebay las que ya entonces calificábamos de actividades mixtas. Se incluyen en este grupo los informes emitidos por órganos administrativos, de los cuales nos ocupamos aqui.

Definimos asi el informe: «Acto administrativo, consistente en una declaración de juicio emitida por un órgano distinto de aquel a quien corresponde iniciar, instruir o resolver el procedimiento, $\mathrm{y}$ que sirve para aportar datos al expediente o comprobar los ya existentes en el mismo.»

\subsection{Naturaleza}

\section{'2.21 Idea general}

Al hilo de la definición propuesta podemos concretar la naturaleza juridica del informe en los siguientes caracteres: $a$ ) es un acto administrativo; b) se emite por un órgano distinto del que inicia, instruye o resuelve el procedimiento; c) es instrumento de aportación de datos procesales o de comprobación de los mismos, y $d$ ) constituye una manifestación del llamado «auxilio administrativo». Examinamos a continuación cada uno de estos caracteres.

\subsection{Acto administrativo}

A) Entendemos por acto administrativo cualquier acto juridico de declaración de voluntad, de conocimiento, de juicio o de deseo, realizado por una Administración pública en el ejercicio de una potestad administrativa distinta de la reglamentaria. 
Partiendo de tal concepción, no es difícil calificar el informe de acto administrativo. Asi se viene aceptando ya por la doctrina que, generalmente, subraya su carácter de acto de trámite.

Afirmada la naturaleza de acto administrativo de los informes de que nos ocupamos, decimos también que constituyen declaraciones de juicio.

B) Ahora bien, aun prescindiendo del llamado informe vinculante - de cuya naturaleza hablaremos después-, hay que reconocer que, a veces, el informe, aun siendo esencialmente declaración de juicio, envuelve, en cierto modo, una declaración de voluntad. Por ejemplo, iniciado el procedimiento para la declaración de «centro o zona de interés turístico nacional», está preceptuado que una serie de órganos administrativos han de elevar al Ministerio de Información y Turismo informe, dentro de su respectivo ámbito de competencia, sobre el centro o zona proyectado (art. 9 de la ley de 28 de diciembre de 1963). Es evidente que en estos informes hay slempre algo más que una declaración de juicio, algo más que una mera opinión. Porque cuando en un expediente cualquiera informa-pongamos por caso-el Consejo de Estado sobre el alcance de un determinado precepto legal, el dictamen tendrá generalmente un carácter aséptico; queremos decir que el citado organismo no tendrá normalmente un interés propio en el asunto. Cosa distinta ocurre en el ejemplo antes citado. Porque el municipio que informa sobre la conveniencia (o no) de establecer un centro de interés turístico sí está interesado en que dicho centro se establezca (o no se establezca). En consecuencia, su informe expresa no sólo su opinión, sino su voluntad, lo que el municipio quiere que se haga (o que no se haga). Por eso la propia ley establece que, transcurrido el correspondiente plazo sin haberse recibido los informes aludidos, «se entenderá evacuado el trámite con la conformidad de los órganos que no los hubieran emitido».

En una palabra, que en el caso citado - y en otros muchos que podrían traerse a colación--el informe no constituye una mera declaración de juicio, sino la conformidad (o disconformidad) del órgano de que se trate. Sin embargo, en una definición del acto administrativo de informe no resulta fácil recoger estos matices, y por ello preferimos decir simplemente que el informe es una declaración de juicio.

C) En este punto, parece conveniente precisar la distinción del informe con la autorización. A nuestro modo de ver, la diferencia puede concretarse en las siguientes notas: 
a) Informe y autorización son actos de diverso contenido psiquico. El informe constituye una manifestación de juicio o de opinión, con la matización que hemos anotado hace un momento. La autorización constituye siempre una declaración de voluntad.

b) Informe y autorización son actos de finalidad distinta. El informe persigue - lo razonamos más adelante-aportar datos al expediente o comprobar los ya existentes en el mismo, permitienao, en definitiva, al órgano decisor apreciar bajo una luz nueva la cuestión sobre la que ha de pronunciarse. La autorización, en cambio, persigue la remoción de un obstáculo que se opone al ejerciclo de un derecho o facultad, y viene a operar como un presupuesto de validez del acto autorizado.

c) Informe y autorización difieren también en cuanto que el primero es obligación y. el segundo facultad del órgano que ha de emitirlos. El órgano informante está obligado a evacuar el informe que se le pide, y si no lo hace puede originarse responsabilidad para el funcionario titular del mismo. Cosa distinta ocurre con la autorización, pues el órgano correspondiente puede normalmente negarse a darla.

d) Por último, informe y autorización se diferencian por su eficacia respecto del acto final a que van referidos. El órgano que informa desfavorablemente en un determinado procedimiento no impedirá - salvo el caso excepcional de que su informe sea vinculante-que la resolución que se dicte tenga un contenido distinto a la tesis por él sustentada. El órgano autorizante, en cambio, podrá siempre impedir que el acto que considera inoportuno se realice, bastando para ello con denegar la autorización cuantas veces se le solicite.

D) La calificación del informe como una declaración de juicio hace ineludible la referencia al problema de la naturaleza juridica de los informes vinculantes, cuestión ésta que examinaremos después. Adelantaremos ya aquí que, aun cuando no es fácil encontrar solución satisfactoria al problema, parece que puede aceptarse la configuración de estos informes vinculantes como verdaderas y propias declaraciones de juicio.

2.23 Se emite por un órgano administrativo distinto de aquel a quien corresponde iniciar, instruir o resolver el procedimiento

Con esta nota se pretende, en alguno de nuestros reglamentos derogados, distinguir el informe de la propuesta de resolución. En 
la doctrina suele admitirse la distinción, generalmente apoyándose en esta nota. $Y$ en la vigente legislación administrativa puede afirmarse, en tesis general, que ambos tipos de actos aparecen diferenciados (art. 91, LPA; art. 105, RPEA), siquiera pueda señalarse alguna norma, todavia vigente, que los trata conjuntamente, calificando las propuestas como «informes para resolver» (arts. 288 y 289, ROF).

En un plano puramente teórico, los informes y la propuesta de resolución, aun cuando posiblemente coincidan en cuanto a su contenido psíquico - ya que también la propuesta puede quizá reputarse declaración de juicio-, parece que deben diferenciarse por razón de la distinta función que cumplen en el procedimiento. El informe tiene una finalidad de tipo instructorio, que, como vamos a ver en seguida, es unas veces de aportación de datos y otras de comprobación de los mismos, dándose normalmente durante la fase de 'instrucción del procedimiento. La propuesta de resolución, en cambio, pertenece a la fase de terminación, sin que pueda decirse que aporte nada el procedimiento ni mucho menos cumpla una finalidad de tipo probatorio. En realidad, la propuesta es un proyecto de resolución, hasta el punto de que no faltan preceptos que le dan una estructura similar a la resolución (art. 105, 1, RPEA; art. 288, ROF). En la práctica, sin embargo, la distinción no resulta tan clara, ni mucho menos. $Y$ así tenemos que el informe de la Asesoría Juridica y del Consejo de Estado parece que han de emitirse con posterioridad a la propuesta de resolución (art. 91, 1) y 2), LPA).

2.24 Es instrumento de aportación de datos procesales o de comprobación de los mismos

Este carácter justifica la calificación de actividad de instrucción de tipo mixto que predicamos de los informes administrativos, y sirve para marcar la distinción entre estos $y$ otros informes, que también pueden darse en el procedimiento administrativo, pero que no son emitidos por órganos de la Administración pública; por ejemplo, los informes emitidos por particulares. $Y$ la distinción puede tener interés a efectos de explicar lo que a primera vista pudiera parecer una anomalía sistemática de la LPA, que trata de los «informes» en una sección distinta de la de la «prueba».

En la legislación común, los informes o dictámenes tienen el valor de medios probatorios (art. 578, LEC; art. 1.215, Cc). 
DA-1966, núm. 98. FRANCISCO GONZÁLEZ NAVARRO. Los informes administrativos como actos de

En la LPA, sin embargo, los informes y la prueba aparecen regulados en secciones distintas. De los informes se ocupa la sección 2. ${ }^{a}$, capitulo III, título IV, y de la prueba, la sección siguiente. Este tratamiento, separado de ambos temas - que, por otra parte, no es nuevo en nuestra legislación procedimental administrativa-, no es probablemente caprichoso. Pero iquiere decir que los informes de órganos administrativos son actos de naturaleza distinta de los actos de prueba?

A primera vista la respuesta afirmativa parece que viene impuesta no sólo por la regulación independiente de los informes y de la prueba, sino incluso por la comparación de los artículos 84,1 ), LPA ( $\&$ A los efectos de la resolución del expediente, se solicitarán aquellos informes...»), y 88, 1), LPA ( LOS hechos relevantes para la decisión de un procedimiento podrán acreditarse por cualquier medio de prueba»). Los informes serían un medio de aportación de datos, y la prueba, un medio de comprobación de los mismos.

Sin embargo, no creemos que pueda negarse que estos informes constituyen muchas veces actividad pericial, y en cuanto tal son un medio de prueba. Los ingredientes que componen el concepto de la pericia-realizarse por un tercero que percibe o enjuicia los datos en virtud de un encargo procesal, y con la finalidad de provocar el convencimiento del órgano decisor-pueden darse en estos informes. (Plénsese, por ejemplo, en un informe emitido por la Jefatura de Obras Públicas de una provincia, a solicitud de la Jefatura Central de Tráfico, sobre si en un punto determinado de una carretera existe o no cambio de rasante.)

Aun siendo esto asi, debe reputarse acertada la regulación separada de los informes y de la prueba, tal como lo hace la .LPA. De una parte, porque cuando la LPA habla de informes se está refiriendo no a cualquier tipo de dictámenes periciales, sino exclusivamente a aquellos que, a petición del órgano instructor del procedimiento, se emiten por organismos administrativos en el ejercicio de la función consultiva. De otra parte, porque estos informes pueden tener eficacia vinculante, lo que no ocurre generalmente en la pericia de la legislación común. Finalmente, porque muchos de estos informes no persiguen propiamente comprobar datos, sino aportar nuevos elementos de juicio al expediente. (Esta será normalmente la finalidad de los dictámenes juridicos.)

Asi, pues, junto a los informes que con valor meramente probatorio puedan aportarse al procedimiento administrativo, están estos otros de naturaleza sui generis, que acertadamente vienen recibiendo un tratamiento separado en la legisiación administrativa y que 
se emiten por órganos administrativos, con la finalidad de aportación de datos o con la de comprobación de los mismos, y de aquí que los hayamos llamado actos mixtos.

\subsection{Constituye una manifestación del llamado «auxilio adminis- trativo»}

Este aspecto de los informes creemos que merece ser subrayado, por cuanto que sirve para explicar la obligación que se establece para el órgano informante de evacuar el dictamen, so pena de incurrir en responsabilidad [art. 86, 3), LPA]. La fundamentación dogmática de esta posible exigencia de responsabilidad creemos se halla en un deber general de los organos administrativos de prestarse mutuamente ayuda. Este deber - que encuentra su paralelo judicial en el deber de jueces y tribunales de auxiliarse mutuamente, que expresamente establece el artículo 284, LEC- no se consagra con carácter general en nuestra legislación administrativa, pero parece que puede inducirse de diversos preceptos, como el articulo 140,2), LPA, o el mismo $32, ' 1$ ), LPA.

En el proyecto de ley de Procedimiento administrativo de la República Federal Alemana -que no ha llegado a ser aprobado en el periodo legislativo que se cerró en julio de 1965-se contiene una interesante regulación del deber de auxilio administrativo (artículos 3 al 7), estableciéndose como principio general que «todos los organos administrativos, debidamente requeridos para ello, deben prestarse recíprocamente una ayuda complementaria». El informe, como manifestación de este. auxilio administrativo, podría estar comprendido en el artículo $4 .^{\circ}, 1$ ), número 3 , del proyecto, que admite la posibilidad de que un órgano administrativo solicite este auxilio cuando «en la ejecución de sus functones está supeditado al conocimiento de hechos que ignora y que por si no puede averiguar»; siquiera para los redactores del proyecto alemán, la emisión del informe parece que no tendrá tal carácter de auxilio administrativo cuando la función propla del órgano sea precisamente la asesora. Así parece que hay que deducirlo de lo que previene el artículo $3 .^{\circ}, 2$, número 2, que dice que no se considera auxilio administrativo «cuando se trata de unos actos que el órgano requerido ejecuta con el carácter de función propia».

Verdaderamente, seria muy interesante que nuestra legislación administrativa incorporara una regulación de tipo general sobre el auxilio administrativo, que vendría, por cierto, a.resolver las espi- 
Estudios

nosas cuestiones que se presentan en la práctica con tanta frecuencia. (Plénsese, por ejemplo, en el problema de la notificación a través de las Corporaciones locales.)

Pues bien, volviendo al hilo de nuestra investigación, entendemos que la actividad de informe, por lo menos cuando se realiza por organos que no la tienen atribuida como especifica y propia, constituye una importantísima manifestación del auxilio administrativo, reveladora de un principlo general latente en nuestro Derecho administrativo de la recíproca colaboración entre los organos de la Administración pública.

\subsection{Regulactón}

\subsection{Idea general}

Si algún rasgo merece destacarse en la vigente regulación del trámite de informe es el de la dispersión normativa. Junto a los preceptos contenidos en la LPA, hay que contar con las normas reglamentarias generales contenidas en varias órdenes de la Presidencia del Gobierno, y con las especiales del RPEA. Y esto sin olvidar los preceptos de la legislación local y las normas reguladoras de los órganos consultivos y de determinadas materias administrativas. Como vamos a ver, no siempre la técnica empleada es la correcta, y, en alguna ocasión, la norma suscita serias dudas sobre su legalidad. Finalmente, hay lagunas que revelan lo insuficiente de la reglamentación dictada.

\subsection{Ley de Procedimiento administrativo de 17 de julio de 1958}

El tema de los informes aparece regulado en la LPA en forma dispersa, técnicamente defectuosa y prácticamente insuficiente.

La dispersión resulta patente con la simple enumeración de los siguientes preceptos, en que se trata de los informes: artículos 8,4 ), y 19,2$)$-conflictos de competencia_; 21, 4) -recusación-; 39, 2) -acumulación obligatoria de procedimientos-; 43,1 ), letra c) -motivación-; 53, 5) -convalidación-; 84, 85 y 86 -núcleo fundamental de preceptos dedicado en la LPA a la regulación del tema-; 91, 2) -informes de la Asesoria Juridica y del Consejo de Estado-; 117 -recursos en general_; 123, 2) -recurso de alzada_; 130 —elaboración de disposiciones generales-, etc. 
El defectuoso tecnicismo de la LPA en este punto se pone de relieve observando que la sección 2.a, capítulo III, título IV, bajo la rúbrica «Informes», acoge dos trámites distintos: los informes o dictámenes de que aqui nos ocupamos y las informaciones públicas. Bien es verdad, sin embargo, que la imprecisión queda limitada a la rúbrica y no trasciende a la regulación. También la exposición de motivos [apartado $\mathrm{V}, 4)$ ], alude por separado a ambos trámites. El artículo 27, LPA, emplea indebidamente la expresión «Informes» para referirse a las informaciones que el particular está obligado a facilitar a la Administración.

Por último, la regulación de la LPA es prácticamente insuficiente, requiriendo una adecuada matización reglamentaria, que sólo en forma parcial se ha hecho.

La exposición de motivos de la LPA no orienta, ni poco ni mucho, sobre el tema, pues se limita a decir: «Por último, entre los actos de instrucción están los informes, tanto preceptivos como facultativos.»

2.33 Orden de la Presidencia del Gobierno de 22 de octubre de 1958

En esta Orden se dictan una serie de disposiciones complementarias de la LPA reglamentando algunos aspectos de la misma. A los efectos de nuestro trabajo, nos interesa la norma $3 .^{a}$, que regula el cuaderno de extractos.

2.34 Orden de la Presidencia del Gobierno de 31 de diciembre de 1958 regulando facultades de los jefes de sección

Esta Orden -como dice su preámbulo- trata de establecer, «en trámites específicos, pero que son comunes a los diferentes departamentos ministeriales», normas mediante las cuales se obtenga la economía, celeridad y eficacia en el procedimiento que señala el artículo 29. LPA.

Entre esos trámites especificos, la orden en cuestión se refiere muy particularmente a los informes, regulando la intervención de los jefes de sección en las peticiones de informes. Más adelante tendremos ocasión de ver cómo el preámbulo de dicha orden justifica minuciosamente esta intervención de los jefes de sección. 
2.35 Reglamento de Procedimiento económico-administrativo de 26 de noviembre de 1959

El artículo 106, RPEA, dentro del capitulo III (terminación), sección 1. ${ }^{\mathrm{a}}$ (resolución) inmediatamente después del articulo que trata de la ponencia o propuesta de resolución, se ocupa de los informes que pueden acordar los tribunales antes de resolver. Se trata, por tanto, de informes que tienen lugar en la fase de terminación, pero su naturaleza es la de actividad instructoria. El Tribunal solicita el informe porque estima que el material instructorio es todavia insuficiente. El articulo 95, 3), RPEA, contiene una referencia al informe que ha de remitir la oficina de gestion.

\subsection{Legislación local}

Los articulos 285 a 289, ROF, regulan, junto al informe propiamente dicho, la propuesta de resolución («informe para resolver»)).

Particular relieve cobra en esta legislación la distinción entre informes juridicos e informes técnicos, por la posibilidad que parece autorizarse de exigir honorarios por estos últimos.

\section{$2.37 \quad$ Normas especiales}

Finalmente, deben ser tenidas en cuenta todas aquellas normas especiales reguladoras de los organos consultivos y de determinadas materias administrativas, a fin de determinar los supuestos en que se exige preceptivamente el cumplimiento de este trámite. En el caso de que en estas normas se contengan disposiciones sobre el procedimiento de los informes, su vigencia vendrá determinada por el juego de las reglas que determinan el ámbito de aplicación de la LPA.

Particular interés ofrecen, entre esas normas especiales, las relativas al Con'sejo de Estado, fundamentalmente los articulos 138 al 150 del Reglamento orgánico de dichó organismo, de 13 de abril de 1945. También merecen citarse las disposiciones del Reglamento orgánico de la Dírección General de lo Contencioso del Estado y del Cuerpo de Abogados del Estado, de 27 de julio de 1943, especialmente los articulos 23 al 31 y 48 al 52. 


\subsection{Clases}

\subsection{Preceptivos $y$ facultativos}

A) Informes preceptivos.-Establece el artículo 84, 1), LPA: «A efectos de la resolución del expediente (mejor debiera decir: del "procedimiento"), se solicitarán aquellos informes que sean preceptivos por disposiciones legales...»

Como este precepto habla de informes preceptivos «por disposiciones legales», se suscita la duda de si podrá establecerse la obligatorfedad de un informe por disposición de rango reglamentario. Porque, en principio, parece que la expresión disposición legal acoge solamente a la ley en sentido formal, y asi se ha interpretado en algún otro caso por la doctrina.

Desde luego, hay casos en que, con referencia a determinados organismos, se exige que la audiencia esté establecida por ley. Así, el articulo $3 .^{\circ}$ del Reglamento del Consejo de Estado de 13 de abril de 1945 dice que «el Consejo de Estado en pleno debe ser oido necesariamente en los siguientes asuntos: ... 5. . Todo asunto en que por precepto expreso de una ley haya de oírse al Consejo de Estado en pleno». También en el artículo $4 .^{\circ}$ del mismo Reglamento se dice: «La Comisión Permanente del Consejo de Estado debe ser oída en los siguientes asuntos: ... 10. Todo asunto en que por precepto legal haya de oírse al Consejo de Estado y no se diga expresamente que debe ser el Consejo en pleno...»

Pero no parece que haya inconveniente para que por norma reglamentaria se imponga la exigencia de informe. $Y$ lo cierto es que encontramos informes preceptivos establecidos por leyes, y otros esestablecidos por reglamentos. Veamos dos ejemplos de cada supuesto:

a) Ley de Centros y zonas de interés turistico nacional de 28 de diciembre de 1963.-El artículo $9 .^{\circ}, 2$ ), dispone que, una vez incoado el expediente para la declaración de «centro o zona de interés turistico nacional», en un plazo no inferior a treinta dias deberán elevar informe al Ministerio de Información y Turismo en relación al proyectado centro o zona, y, dentro de su ámbito territorial de competencia, los órganos que señala (gobernadores civiles, corporaciones locales, Dirección General del Patrimonio del Estado cuando afecta a bienes del Estado, etc.).

b) Ley de Contratos del Estado de 8 de abril de 1965.-Los artículos 11 y 12 establecen el informe «previo y preceptivo» de la Junta Consultiva de Contratación Administrativa del Ministerio de Hacienda y del Consejo de Estado para determinados supuestos. 
c) Decreto de 14 de mayo de 1964 por el que se aprueba el Reglamento de los servicios de Correos.-El artículo 54 establece como «trámite previo esencial», en el procedimiento de autorización de nuevos tipos de máquinas de franquear, el informe técnico del servicio de Ingeniería de la Dirección General de Correos.

d) Orden de 7 de julio de 1965, del Ministerio de Educación Naclonal, por la que se dictan normas a los rectorados de las distintas universidades para resolución de las peticiones de traslados académicos de alumnos universitarios.-Exige «informe favorable» del rectorado de la universidad en que radique el expediente académico del interesado.

Por ello entendemos que, aunque la LPA hable en el articulo 84, 1), de «nformes que sean preceptivos por disposiciones legales», este tipo de informes puede ser establecido también por normas reglamentarias.

B) Informes facultativos.--El artículo 85, 2), LPA, dice que, «salvo disposición expresa en contrario, los informes serán facultativos...».

Alguna vez se ha sugerido la, conveniencia de revisar este precepto, porque «lo exacto es precisamente lo contrario, que, salvo disposición expresa, los informes son preceptivos; si la norma no habla de informes, el órgano competente puede solicitarlos; si dice que el órgano resolverá oyendo o no a otro, o que antes de resolver puede pedir informe, éste es tamblén facultativo; pero si la norma dice $-y$ es el supuesto general cuando habla de informes-que el órgano competente resolverá previo informe de tal otro, aun sin decir que ese informe es preceptivo, ciertamente lo es; es decir, que no puede aquél resolver válidamente sin haber solicitado el informe».

A nuestro modo de ver, el precepto es correcto en su actual redacción. Cierto que, generalmente, cuando se habla de informes, se hace para aludir a los de carácter preceptivo. Es lógico que asi sea. Precisamente han de exigirse expresamente, porque constituyen la excepción.

\subsection{Vinculantes, semivinculantes $y$ no vinculantes}

A) Normalmente, el órgano competente para resolver tiene libertad para seguir o no el parecer del órgano consultivo. En ocasiones, sin embargo, el organo decisor. queda vinculado por el informe, no pudiendo apartarse de la opinión sustentada en el mismo. Conforme al artículo 85,2), LPA, «salvo disposici.u c cpresa en contrarlo, los Informes serán... no vinculantes». El Decreto de 30 de novlembre de 
1961, sobre actividades molestas, nocivas, insalubres y peligrosas, regula (art. 33) un supuesto especial que puede calificarse de informe semivinculante. A veces, en el lenguaje legal se rehuye la expresión informe vinculante, sustituyéndola por la de informe favorable. Aun cuando el resultado es el mismo, algún autor ha intentado matizar diciendo que, cuando lo que se requiere es informe favorable, el dictamen podría calificarse, más que de vinculante, de obstativo.

El Reglamento de oposiciones y concursos, de 10 de mayo de 1957, contrapone (art. 13) las propuestas del Tribunal «que consistan en meros informes» y las que «vinculan a la Administración». Pudiera pensarse que - con una terminologia impropia - se está refiriendo a un supuesto de informe vinculante. No hay tal. Se trata de una propuesta de resolución que - contra lo que suele ser normal en este tipo de actos-es vinculante. O sea, que al igual que ocurre con los informes, puede hablarse de propuestas vinculantes y no vinculantes.

B) Los informes vinculantes han suscitado cuestión doctrinal sobre su auténtica naturaleza, habiéndose llegado, incluso por algún autor, a sugerir la conveniencia de estudiar separadamente los actos vinculantes de aquellos del mismo tipo carentes de tal eficacia.

Las posturas doctrinales, oscilan entre dos criterios extremos:

a) Los informes vinculantes constituyen puras y simples declaraciones de juicio. Si después el órgano activo ha de adecuar su actuación a tales declaraciones, ello deriva no de la distinta naturaleza del acto, sino más bien de la circunstancia de que la ley, por razones particulares de oportunidad, asi lo exige en casos determinados.

b) Frente a esta postura, se argumenta que no debe prescindirse de los efectos que se ligan a la declaración en que el informe consiste, y si verdaderamente el órgano decisor no puede desligarse de la opinión del órgano consultivo, quiere decir que la declaración de este viene considerada como verdadera y propia declaración de voluntad.

¿Cuál de estas dos posturas debe aceptarse? Realmente no puede decirse que sea fácil hallar una respuesta absolutamente satisfactoria a esta interrogante. Quizá lleve razón quien afirma que en muchos casos la denominación de «informes» se mantiene, no obstante su eficacia vinculante que los convierte en verdaderas resoluciones, bien por razones históricas, pues inicialmente tuvieron el carácter de una mera opinión o consulta que el órgano decisor era libre de seguir o no, bien por razones de tipo politico, con objeto de enmascarar lo que realmente constituye un efectivo desplazamiento de la competencia decisoria. Sin embargo, no puede perderse de vista que la calificación 
del informe vinculante como una resolución o, mejor, como una verda'dera decisión parece que chocaría con la regulación legal, donde los informes - sean o no vinculantes-reciben un tratamiento unitario $\mathrm{y}$, desde luego, separado del de la decisión administrativa.

$Y$ lo cierto es que tal vez pudiera encontrarse una explicación de los informes vinculantes que permita sostener su naturaleza de verdaderas y propias declaraciones de juicio. Al respecto, puede tener interés recordar aqui la distinción que los procesalistas hacen, al estudiar la naturaleza jurídica de la sentencia, de dos elementos integrantes de la misma: el juicio lógico, consistente en la comparación de la pretensión de la parte con la norma aplicable, y la declaración de voluntad del juez o tribunal. Proyectando esta distinción al problema que examinamos, tendremos que en el supuesto de que el órgano decisor esté obligado a decidir conforme a la opinión del órgano consultivo, se ha producido por ley una escisión de esos dos elementos que normalmente aparecen unidos: el juicio lógico se remite al órgano consultivo y la declaración de voluntad se sigue residenciando en el órgano decisor.

C) La eficacia vinculante se atribuye unas veces por norma legal y otras por norma de rango reglamentario. Recogemos a continuación dos ejemplos de uno y otro supuesto:

a) Los artículos 109 y 110, LPA, requieren informe favorable de1 Consejo de Estado para que la Administración pueda declarar nulos o anular determinados actos.

b) Según la base $5 .^{2}$ de la ley de 17 de octubre de 1941, regulando los Tribunales de Honor, cuando el tribunal acuerde la separación del inculpado se remitirán las actas al Consejo de Estado para que en el plazo más breve posible informe sobre si ha habido o no quebrantamiento de forma, siendo vinculante su dictamen a efectos de la validez de lo actuado.

c) El artículo 55 del reglamento de los servicios de Correos, en el procedimiento antes citado de autorización de nuevos tipos de máquinas de timbrar establece que «si el informe técnico de ingenieria fuese desfavorable, la solicitud será desestimada...»

d) La orden del Ministerio de Educación Nacional de 7 de julio de 1965, antes citada, prevé igualmente un informe de carácter vinculante.

Asi, pues, el articulo 85, 2), LPA, que habla genéricamente de disposición, utillza una expresión correcta. 
DA-1966, núm. 98. FRANCISCO GONZÁLEZ NAVARRO. Los informes administrativos como actos de

A la doble clasificación ya estudiada - preceptivos y facultativos, vinculantes y no vinculantes- podrian añadirse otras que, desde distinta perspectiva, permiten tener una visión más completa del tema.

A) Particular interés of recen, desde el punto de vista estrictamente procedimental, los informes sobre proyectos de disposiciones, expresamente aludidos en los artículos 130, 2), y 131, 1), LPA.

B) La distinción entre informes jurídicos y no jurídicos (generalmente calificados de técnicos) no parece debiera tener mayor trascendencia que la puramente sistemática de reflejar su diverso contènido. Sin embargo, y como tendremos ocasión de ver, nuestra legislación local parece querer darle una injustificable significación económica.

C) El Reglamento orgánico de la Dirección General de lo Contencioso del Estado y del Cuerpo de Abogados del Estado, de 27 de julio de 1943, dice que los abogados del Estado que tengan a su cargo el Servicio de lo Consultivo en la provincias deberán asesorar verbalmente o por escrito a las autoridades del Estado en las provincias, «cuidando de que los informes sean razonados y citando las disposiciones que sean aplicable» (art. 50, 1). A nuestro modo de ver, y a virtud de lo establecido en la disposición final primera, párrafo primero, inciso final, de la LPA, las normas de procedimiento que se contienen en este reglamento están en vigor hoy dia en lo que no contradigan a este texto fundamental. Como quiera que los informes de que hablan los artículos 84 a 86, LPA, son evidentemente informes emitidos por escrito, podría pensarse que el transcrito precepto of rece contradicción con las normas de la LPA. Sin embargo entendemos que no es así, ya que parece no ofrecer duda que del asesoramiento verbal del artículo 50 del reglamento se deja también constancia escrita como resulta de la exigencia de que el informe sea razonado con cita de las disposiciones aplicables. Esto aparte de que el acto administrativo emitido en forma verbal está admitido en el articulo 41,2), LPA, en el que se dice que «en los casos en que los órganos administrativos ejerzan su competencia en forma verbal, y no se trate de resoluciones, la constancia escrita del acto, cuando sea necesaria, se efectuará y firmará por el organo inferior que lo reciba oralmente, expresando en la comunicación del mismo la autoridad de que procede, mediante la fórmula 'De orden de...'». En el precepto del reglamento transcrito nos encontramos con un supuesto de ejercicio de competencia en forma verbal que no hay inconveniente en incluir en este artículo 41, 2), LPA, aun cuando el supuesto para que esté pensado no sea el mismo, según revela la estrechez de la fórmula ( $(\mathrm{De}$ orden de...») exigida. 
D) Finalmente, puede hablarse de informes espontáneos y de informes provocados, clasificación ésta que permite acoger el supuesto contemplado en el artículo 18 de la ley Orgánica del Consejo de Estado, de 25 de noviembre de 1944. Entendemos que las normas de tipo procedimental contenidas en esta ley y en su reglamento están en vigor hoy dia con preferencia a la LPA, que se aplicará con carácter supletorio, en cuanto constituyen normas de actuación de un organo colegiado (art. 1, 2), LPA, disposición final 1.a, 3), LPA y artículo $1,3 .^{\circ}$ del decreto de vigencias de la LPA, de 10 de octubre de 1958).

\section{Procedimiento}

\subsection{IDEA GENERAL}

El informe, acto de trámite en un determinado procedimiento, constituye a su vez acto final de otro procedimiento especifico: aquel que va dirigido concretamente a la obtención del informe mismo.

Con carácter general se ha escrito en alguna ocasión: «El procedimiento tiene una extensión menor o mayor según que la coordinaclón de actividad juridica tienda a conseguir un resultado que podremos llamar, según los casos, parcial o total: hay, por tanto, un procedimiento que tiende a la formación del efecto jurídico final y hay otro que mira a la formación de uno de los elementos del primero. El procedimiento a través del cual la Administración dicta un acto que afecta a los particulares, por ejemplo, el nombramiento de un funcionario público, una concesión, presupone muchas veces la emisión de un dictamen, una propuesta, la petición de una autorización, una instrucción, etc., pero a su vez el dictamen o los otros elementos del procedimiento necesitan de un proceso de formación: la petición del dictamen por parte de la Administración activa, la convocatoria del colegio consultivo, la votación, la redacción del dictamen aprobado, la comunicación al órgano que lo ha pedido. Entre las dos especies de procedimlento no existe, sin embargo, una diferencia sustancial, sino meramente cuantitativa; de donde resulta que todo lo más se podria hablar de un «procedimiento simple» en la hipótesis de que se trate del proceso formativo de cada acto y de un «procedimiento complejo» en el caso de que deba examinarse el proceso generador del efecto jurídico final».

Vamos, pues, a examinar el procedimiento que se desarrolla en fun- 
ción de un determinado dictamen, distingulendo dos fases fundamentales: la petición del dictamen y la elaboración y remisión del mismo al órgano que lo solicitó.

\subsection{PETICIÓN DEI INFORME}

\subsection{Sujeto}

A) Este tema-regulado con singular precisión en alguno de nuestros reglamentos derogados-aparece silenciado en la LPA. Sin embargo, nuestro Derecho positivo of rece base para distinguir entre el órgano que acuerda pedir el informe y el que firma la petición. Así, en el artículo 20 de la ley orgánica del Consejo de Estado, de 25 de noviembre de 1944, y en el artículo 138 del reglamento de dicha ley, de 13 de abril de 1945, se dispone que las consultas al Consejo se acordarán por el Jefe del Estado, el Gobierno o los ministros, haciendo constar el acuerdo en el expediente respectivo y firmando la orden de remisión del asunto el jefe del Gobierno, en los dos primeros casos, y el ministro del Departamento a que corresponda la consulta, en el último. El RPEA establece que el acuerdo de petición de informe se toma por el Tribunal, solicitándose por el presidente (art. 106).

B) Por otra parte, el tema ha sido abordado con cierto detalle por la Orden de la Presidencia del Gobierno de 31 de diciembre de 1958, en la que, con el declarado propósito de agilizar el procedimiento, se sale al paso al hábito inveterado en la Administración «de que por los ministros o autoridades con firma delegada se decrete el pase de determinados expedientes a informe o consulta de órganos administrativos».

Sobre la base de distinguir entre dictámenes preceptivos y facultativos se establece en dicha orden:

a) Informes preceptivos.-El jefe de sección lo solicitará directamente, invocando el precepto de que se trate (preámbulo y norma $3 .^{\mathbf{a}}$ ).

b) Informes facultativos.-Hay que distinguir:

- Expedientes que por hábito administrativo se pasan a informe de un órgano o Cuerpo consultivo.

Se dispone que «por los Departamentos ministeriales se dictarán y publicarán, en el plazo más breve posible, ordenes en las que se hagan constar los expedientes que, a juicio del titular del Departamento, hayan necesariamente de ser completados con el informe de algún Cuerpo consultivo u organismo de la Administración o de Corporaciones públicas» (norma 4.a). 
Naturalmente, esto vendría a ser algo así como el reconocimiento por vía reglamentaria de una práctica administrativa, de forma que los que eran informes facultativos se convierten en preceptivos.

Por eso se establece que, «en lo sucesivo, en estos casos, los jefes de sección actuarán en la forma indicada en el punto $3 .^{\circ}$ de esta orden» (norma $4 .^{2}$, inciso final), es decir, que también en este caso será el jefe de sección quien lo solicitará directamente, invocando la orden correspondiente.

- Expedientes en que, precisamenté por su carácter excepcional, es el titular del Departamento o la autoridad por él delegada quien decida si han de completarse con algún informe (preámbulo de la orden citada).

\subsection{Forma}

El escrito en que se solicita el informe ha de contener una serie de requisitos preceptivos:

a) Indicación expresa del precepto que lo exija (si se trata de informe preceptivo) o fundamentación de la conveniencia de reclamarlo (si es facultativo) (art. 84, 1), LPA).

b) Delimitación concreta del extremo o extremos acerca de los que se solicita el dictamen (art. 84, 2), LPA).

c) Plazo legal establecido al efecto para la emisión del dictamen (art. 75, 3), LPA).

\subsection{Documentos que deben acompañarse}

Al escrito conteniendo la petición de informe se acompañará, en su caso:

a) El expediente.-Debiendo advertirse:

- Que la LPA no establece ninguna regla general al respecto.

- Que, no obstante, en algunos supuestos alude concretamente a la obligación de remitir el expediente. Así, en el articulo 19, 2), LPA (conflictos de atribuciones), en el 123, 2), LPA (recurso de alzada), etc.

- Que la Orden de 31 de diciembre de 1958 parece dar por supuesta esta remisión (norma $3 .^{a}$, in fine).

- Que el RPEA advierte que «por lo general no se remitirán los expedientes al organismo del que se interese el informe, sino que 
se concretará en la forma que se estima más conveniente el extremo o extremos acerca de los que se solicite el dictamen (art. 106, 3).

b) Cuaderno de extractos.-Se regula con carácter general en la norma tercera de la Orden de 22 de octubre de 1958, que dice asi:

"Cuando así se considere necesario, y desde luego cuando se trate de expedientes en los que haya de informar el Consejo de Estado, se formará cuaderno de extractos, en el que, con indicación de fecha y folio, se resumirán los documentos que componen el expediente; se extenderán las propuestas, notas y contranotas a que pudieran dar lugar y se le incorporarán aquellos informes y documentos cuya exhibición pudiera ocasionar perjuicios a los intereses generales o a tercero, según acuerdo motivado de la autoridad competente para la resolución.»

«El trámite a que se refiere el articulo 91 de la ley de Procedimiento administrativo no alcanzará a dicho cuaderno.»

Como es sabido, la doctrina ha puesto reparos muy justificados a la legalidad de esta norma en cuanto permite excluir del trámite de audiencia determinados documentos.

c) Proyecto de disposición.-En el procedimiento de elaboración de disposiciones de carácter general (título VI, capítulo I, LPA), se exige la remisión del proyecto correspondiente (arts, 130, 2), y 131, 1), LPA). El Reglamento del Consejo de Estado dice que «cuando el informe tenga por objeto un proyecto de disposición legal o reglamentaria, el ministerio consultante acompañará dos copias autorizadas del proyecto, una de las cuales quedará en el archivo del Consejo» (artículo 138,4$)$.

\subsection{Tiempo}

El informe habrá de pedirse cuando lo mande la norma que lo establezca como preceptivo, o cuando se juzgue conveniente, si es facultativo.

La LPA, de acuerdo con el criterio de flexibilidad que la inspira, se produce en términos muy amplios al respecto, diciendo al ocuparse del trámite de audiencia que éste «será anterior al informe de la Asesoría Jurídica y del Consejo de Estado» (art. 91, 2), LPA). El RPEA dice que el informe tendrá lugar «antes de dictar resolución» (art. 106). 


\subsection{ELABORACIÓN Y REMISIÓN DEL INFORME}

\subsection{Sujeto}

El informe habrá de ser emitido por el órgano del que se ha solicitado, si recae dentro del ámbito de su competencia. El RPEA habla de «dictamen de cualquier organismo, corporación, centro o dependencia oflcial» (art. 106, 1), RPEA), y de «organismo del que se interese el informe» (art. 106, 2), RPEA).

En la LPA no se alude al órgano emisor del dictamen, pero es evidente que éste podrá ser individual (Asesoría Juridica, por ejemplo) o colegiado (Consejo de Estado, etc.).

\subsection{Forma}

A) Forma de elaboración.-Cuando el órgano encargado de emitir el dictamen es un órgano individual, este momento del procedimiento suele tener escasa trascendencia. Si por el contrario se trata de un organo colegiado, su actuación of rece ya una cierta complejidad, aplicándose las normas específicas que regulen la actuación del órgano colegiado en cuestión $y$, supletoriamente, las de la LPA sobre este tipo de organismos (arts. 9 al 15, LPA).

B) Forma del dictamen.-Se establece con carácter general que los informes serán sucintos y no se incorporará a su texto el extracto de las actuaciones anteriores (art. 86, 1), LPA).

El Reglamento orgánico del Consejo de Estado establece con mayor rigor que «en la redacción de los dictámenes se expondrán separadamente los antecedentes de hecho, las consideraciones de Derecho y la conclusión o conclusiones, las cuales, en casos justificados, podrán formularse de modo alternativo o condicional», y que «cuando se trate de ... conflictos jurisdiccionales, el dictamen adoptará precisamente la forma de proyecto de decisión resolutoria con resultandos y considerandos» (art. 148, 1) y 2).

\subsection{Documentos que deben acompañarse}

Con el informe' se devolverán los documentos recibidos y que sirvieron de base para la consulta (expediente, cuaderno de extractos, etc.).

El Reglamento orgánico del Consejo de Estado prevé que «en los informes sobre cualquier proyecto de disposición legal, recopilación o 
refundición y reglamentos, el Consejo podrá acompañar a su informe un nuevo texto, en el que figure íntegramente redactado el que, a su juicio, deba aprobarse» (art. 148, 3).

\subsection{Tiempo}

A) Ley de Procedimiento administrativo.-Dispone que «los informes serán evacuados en el plazo de diez dias, salvo disposición que permita otro mayor, que en ningún caso excederá de dos meses (artículo 86, 2), LPA), En este sentido, el artículo 123, 2), LPA, establece el plazo de diez días para la remisión del recurso de alzada, junto con el expediente y su informe en el caso de que aquél hubiese sido pre-. sentado ante el órgano que dictó el acto impugnado.

Pero hay reglas especiales en la LPA estableciendo plazos menores al de diez días. Asi, en el artículo 8, 4), LPA (ocho días), y en el 19, 2), LPA (tres dias).

B) Reglamento de Procedimiento económico-administrativo.-Los informes habrán de emitirse por el órgano consultado en el plazo de un mes, a contar desde la fecha en que reciba la petición (art. 106, 1), RPEA).

C) Reglamento orgánico del Consejo de Estado.-Se distingue entre consultas ordinarias y urgentes (art. 145). Durante el turno de vacaciones - del 15 de julio al 15 de septiembre-sólo se despacharán las consultas declaradas urgentes por acuerdo del Consejo de Ministros (art. 146).

\section{Efectos}

\subsection{DeL INFORME}

\subsection{Eficacia sobre la resolución}

A) Eficacia decisoria.-En el caso de que el informe fuese vinculante vendrá obligada la Administración a dictar su resolución de conformidad con la opinión sustentada por el organismo informante, y de aquí las dudas que se suscitan en torno a la calificación jurídica de este tipo de informes.

Normalmente, sin embargo, el informe será no vinculante, y en cuanto tal constituye un elemento de juicio, un antecedente que de- 
berá tenerse en cuenta al dictar la resolución, pero que carecerá de eficacia en tanto en cuanto no haya sido incorporado por la Administración a la resolución que dicte. A estos informes no vinculantes parece que se refieren los artículos 43,1 ), letra c), y 93, 3); LPA:

a) «Serán motivados, con sucinta referencia de hechos y fundamentos de Derecho: ... c) Las (actos) que se separen... del dictamen de órganos consultivos») (art. 43).

b) "La aceptación de informes o dictámenes servirá de motivación a la resolución cuando se incorporen al texto de la misma» (art. 93, 3).

Tratándose de dictámenes del Consejo de Estado se dispone expresamente en el Reglamento de 13 de abril de 1945 que «las resoluciones que recaigan en los expedientes en que hubiere informado el Consejo deberán contener la mención de su dictamen y exponer si la resolución se ajusta íntegramente a él o se separa del mismo, empleando precisamente las fórmulas: «De conformidad con el Consejo de Estado en pleno» o «en Comisión Permanente», en el primer caso, $\mathbf{y}$ «oído el Consejo de Estado en pleno» o «en Comisión permanente», en el segundo. Cuando se siguiere el criterio de un dictamen aprobado por unanimidad, deberá decirse: «De acuerdo con la mayoria», o bien «con la minoria» o "con el voto particular formulado por ... en el Consejo de Estado".»

B) Comunicación de la resolución al organismo informante.-La resolución recaida en un procedimiento que haya sido objeto de consulta debe comunicarse al organismo emisor del dictamen. Esto no lo dice expresamente la LPA, pero parece que el supuesto puede encajar en el artículo 78, 3), LPA: «Cuando alguna autoridad u órgano intermedio deba tener conocimiento de la comunicación, se le enviará copia de la misma.»

El Reglamento del Consejo de Estado prevé expresamente que «los subsecretarios de los departamentos consultantes o, por su delegación, los directores generales correspondientes estarán obligados a comunicar a la Secretaria General del Consejo, en el término de los quince dias siguientes a la decisión del asunto, las resoluciones recaídas en los expedientes que hubleren sido objeto de consulta, indicando si la resolución se dicta de conformidad o bien oído el Alto Cuerpo» (artículo 143).

C) Publicacion.-El informe, como el resto de las actuaciones del procedimiento administrativo, no puede ser publicado. Excepcionalmente, sin embargo, puede ser alterada esta regla. Así, el Reglamento 
del Consejo de Estado autoriza, bajo ciertas condiciones, la publicación de la doctrina legal sentada en sus informes. En este sentido, dice el artículo 150 de dicho Reglamento:

«El Consejo no podrá publicar sus dictámenes, de no existir precepto legal que disponga su puiblicación, sin la autorización expresa de la autoridad consultante. Esto no obstante, podrá el Consejo, omitiendo los datos concretos sobre la procedencia y características de las consultas, publicar recopilaciones de la doctrina legal sentada en sus informes.»

El reconocido prestigio de que goza el Consejo de Estado confiere trascendencia grande a esta publicación de la doctrina contenida en sus dictámenes, y asi ha sido puesto de manifiesto en alguna ocasión. Es lástima, sin embargo, que los volúmenes hasta ahora aparecidos tengan una circulación muy restringida, ya que no se venden al público, siendo difícil su adquisición.

\subsection{Eficacia excluyente}

El hecho de que un organismo haya dictaminado en un determinado procedimiento no impide que posteriormente intervengan en el mismo procedimiento otros órganos asesores. Esta regla general tiene su excepción en el reglamento del Consejo de Estado:

«Después de ser oído en un asunto el Consejo de Estado en Pleno, no podrá informar en él ningún otro Cuerpo u oficina del Estado. En los que hubiere informado la Comisión permanente sólo podrá informar el Consejo de Estado en plenon (art. 141).

\subsection{Honorarios profesionales e informes}

Parece lógico que siendo el informe una actuación emanada de un órgano de la Administración del Estado en el ejercicio de la función consultiva que tiene atribuida como propia, no pueda el funcionario titular de ese órgano exigir el pago de honorarios profesionales por la emisión del dictamen, ya que en realidad esta actuación forma parte de las prestaciones que ha de dar a la Administración. El problema se aborda por el articulo 287, ROF, con relación a los informes jurídicos. Dịce así el citado precepto:

"Cuando la Corporación cuente con asesores jurídicos que sean funcionarios, corresponderá a éstos emitir los dictámenes en Derecho que aquélla o su presidencia les pidan, y no podrán formular 
DA-1966, núm. 98. FRANCISCO GONZÁLEZ NAVARRO. Los informes administrativos como actos de

minutas ni percibir remuneración por tal motivo. Si no.tuvieren dicha conceptuación de funcionarios se estará a lo pactado o a lo establecido en el correspondiente nombramiento.s

No parece, sin embargo, que se adopte la misma solución por nuestra legislación local en lo que respecta a los informes que no sean juridicos. Así, el articulo $8, R F$, aludiendo a las prestaciones que no exijan dedicación primordial y permanente de la actividad dice que «cuando el profesional tenga, además, la condición de funcionario, y rijan aranceles oficiales para la prestación de los servicios convenidos, sus honorarios se cifrarán en un cincuenta por ciento de los normales».

Más claramente todavia, la ley de 20 de julio de 1963, regulando los emolumentos de los funcionarios de la Administración local, enumera entre las gratificaciones o mejoras que no están incluidas en el concepto de emolumentos «las percepciones de honorarios o derechos facultativos por trabajos profesionales especiales, sujetos a tarifas o aranceles oficiales o de fondos concertados que los sustituyan» (artículo 2,1 ), letra i). $Y$ el número 8,1 ) de la orden del Ministerio de la Gobernación de 17 de octubre de 1963, por la que se aprueba la Instrucción número 2 para la aplicación de la ley de 20 de julio de 1963 citada, dice: «Funcionarios que pueden percibir honorarios o derechos facultativos.-Sólo los funcionarios pertenecientes a la plantilla de técnicos de la Corporación podrán percibir honorarios o derechos facultativos por los trabajos de su especialidad, siempre que dichos honorarios o derechos se hallen sujetos a tarifas o aranceles oficiales de aplicación obligatoria y no meramente orientadores, y en el nombramiento expedido al funcionario se le haya reconocido explícitamente tal derecho.»

Este privilegio que parece asi establecerse para los llamados técnicos de la Corporación -que serán a estos efectos los enumerados en el artículo 240, 4), ROF, con exclusión de los letrados asesores, por aplicación en este último caso del artículo 287 , ROF-es absolutamente inaceptable. 


\subsection{DE LA NO PETICIÓN DE INFORMES PRECEPTIVOS}

\subsection{Anulabilidad de la resolución que pone fin al expediente}

No dice con carácter general la LPA cuáles son las consecuencias de la omisión de informes preceptivos, pero es evidente que estaremos ante un caso de anulabilidad por aplicación del artículo 48, LPA, pues el acto habrá incurrido en una infracción del ordenamiento juríaico que, además, determinará normalmente que el acto carezca de los requisitos formales indispensables para alcanzar.su fin.

El Tribunal Supremo, que ha tenido ocasión de pronunciarse reiteradamente sobre la omisión de informes preceptivos, confirma esta interpretación. Asi, la STS, Sala 4. a, de 18 de marzo de 1965, Aranzadi número 1753 , refiriéndose a un supuesto de omisión de un asesoramiento técnico preceptivo, declara anulable el acto por haberse producido a causa de tal omisión lá indefensión del interesado, aclarando que «las dos caracteristicas, que, para que el acto administrativo sea anulable señala el párrafo $2 .^{\circ}$ del artículo 48 de la ley de Procedimiento administrativo - carencia de requisito formal e indefensión-, no tienen que concurrir ambas, sino que, según el texto del referido precepto, como revela la conjunción "o» en él empleada, basta con que se dé una de ellas, aparte de que, en un concepto amplio de la indefensión en el sentido de dificultad en el apoyo de una pretensión, ino puede negarse que implique tal dificultad la omisión de un asesoramiento técnico que la enjuicie; y ello no sólo cuando el informe resulte favorable a ella, sino en cuanto sirve para precisar o aclarar los términos y aspectos de la cuestión». En análogo sentido, la STS, Sala $4 .^{\text {a }}$, de 19 de septiembre de 1963, Aranzadi núm. 3267, declara anulable un expediente administrativo en que falta la preceptiva audiencia del Consejo de Estado, invocando los artículos 48 y 50, LPA, y 4, Cc.

En algunas disposiciones anteriores a la LPA, por ejemplo, en el reglamento de la Dirección General de lo Contencioso y del Cuerpo de Abogados del Estado (art. 51) se atribuye a la omisión de informes preceptivos la consecuencia de la nulidad. A la vista de la nueva legislación parece que habrá que entender modificados estos preceptos en el sentido de que el acto será simplemente anulable. 


\subsection{Subsanación}

A primera vista puede pensarse que si el acto dictado con omisión de un informe preceptivo es simplemente anulable, este vicio debería poder subsanarse por aplicación de la regla general del artículo 53, 1), LPA. Sin embargo, la redacción de los párrafos 4) y 5) de este mismo artículo no deja lugar a dudas de que la regla general tiene en este caso una excepción:

4) «Si el vicio consistiese en la falta de alguna autorización, podrá ser convalidado el acto mediante el otorgamiento de la misma por el órgano competente.»

5) «Lo dispuesto en el párrafo precedente no será aplicable a los casos de omisión de informes o propuestas preceptivos.)

La excepción consignada por el legislador, siguiendo en este punto lo propugnado por la doctrina, tiene un fundamento evidenté, pues el informe preceptivo está destinado precisamente a ilustrar al órgano en el momento de dictar la resolución, por lo que si ha sido omitido hay motivos para pensar que la resolución puede ser diferente de la que en otro caso tal vez se hubiese dictado.

El reglamento del Consejo de Estado dispone que "el presidente del Consejo, en nombre de éste, llamará la atención a quien corresponda cuando en el despacho de algún asunto se hubiere omitido indebidamente su audiencia, y podrá reclamar el expediente correspondiente para que se subsane el defecto» (art. 144).

\subsection{DEL SILENCIO DEL ORGANISMO INFORMANTE}

4.31 Prosecución de las actuaciones y posible exigencia de responsabilidad,

A) Ley de Procedimiento administrativo: «De .o recibirse (el informe) en el plazo señalado, podrán proseguirs', las actuaciones sin perjuicio de la responsabilidad en que incurra el funcionario culpable de la demora» (art. 86, 3).

B) Reglamento de Procedimiento económico-administrativo: «Si transcurrido el plazo de un mes no se hubiere recibido el informe interesado, se cursará el oportuno recordatorio, y al cumplirse el de dos meses desde el envio de la primera p stición proseguirán las actua- 
ciones hasta dictarse la resolución, sin perjuicio de la responsabilidad en que pudiera haber incurrido el funcionario culpable de la omision» (art. 106, 4).

Este recordatorio-que funciona a modo de denuncia de morasupone una peculiaridad del RPEA respecto de la LPA.

\subsection{Valoración positiva}

A veces, el silencio del órgano informante tiene atribuido un valor afirmativo en la ley. Así, por ejemplo, en el artículo 9, 3) de la ley de 28 de diciembre de 1963 sobre centros o zonas de interés turistico nacional.

También parece que debe incluirse aqui el artículo 39, 2), LPA, que habla (inciso primero) de «informes y autorizaciones», y que establece (inciso tercero) la posibilidad de exigir responsabilidad al funcionario o autoridad obligado a emitir el informe, pudiendo pensarse que el supuesto de silencio positivo que prevé (inciso segundo) va referido indistintamente a la omisión del informe o de la autorización.

\section{Conclusiones}

5.01 Los informes de que aquí nos ocupamos pueden ser definidos como actos administrativos consistentes en una declaración de juicio emitida por un órgano distinto de aquel a quien corresponde iniciar, instruir o resolver el procedimiento, y que sirve para aportar datos al expediente o comprobar los ya existentes en el mismo.

5.02 Aun prescindiendo del llamado informe vinculante-sobre cuya naturaleza tanto se discute-, hay que reconocer que, a veces, el informe, aun siendo esencialmente declaración de juicio, envuelve, en cierto modo, una declaración de voluntad. Sin embargo, en una definición del acto administrativo de informe no resulta fácil recoger estos matices, $y$ por ello preferimos decir simplemente que el informe es una declaración de juicio.

5.03. No debe confundirse el informe con la autorización. Ambos actos tienen distinto contenido psíquico, persiguen distinta finalidad y producen una eficacia diversa.

5.04 En un plano puramente teórico, los informes y la propues̀- 
ta de resolución, aun cuando posiblemente coincidan en cuanto a su contenido psiquico, parece que deben diferenciarse por razón de la distinta función que cumplen en el procedimiento: los informes son actividades de instrucción, la propuesta de resolución pertenece a la fase de terminación. En la práctica, sin embargo, la distinción no resulta $\tan$ clara, ni mucho menos.

5.05 El informe constituye muchas veces actividad pericial, $y$ en cuanto tal es un medio de prueba. Pero otras veces el informe no persigue propiamente la comprobación de datos procesales, sino aportar nuevos elementos de juicio al expediente. De aqui que pueda calificarse el informe como actividad de instrucción de tipo mixto.

5.06 La actividad de informe, por lo menos cuando se realiza por órganos que no la tienen atribuida como especifica y propia, constituye una importantísima manifestación del auxilio administrativo, reveladora de un principio general latente en nuestro Derecho adminístrativo de la reciproca colaboración entre los órganos de la Administración pública.

5.07. La vigente regulación de los informes en el procedimiento administrativo es dispersa, defectuosa e insuficiente.

5.08 Aunque el artículo 84, 1), LPA, habla de informes preceptivos «por disposiciones legales», no parece que haya inconveniente para que por norma reglamentaria se imponga la exigencia de informes. $Y$ lo cierto es que encontramos informes preceptivos establecidos por leyes y otros establecidos por reglamentos.

5.09 Parece que puede sostenerse la configuración del informe vinculante como verdadera declaración de juicio, sobre la base de separar los dos elementos de la decisión administrativa: el juicio lógico se remite al órgano consultivo y la declaración de voluntad se sigue residenciando en el órgano decisor.

5.10 A la doble clasificación que recoge el artículo 85, 1), LPA -preceptivos y facultativos, vinculantes y no vinculantes-pueden añadirse otras que ofrecen perfiles de un cierto interés: jurídicos y no juridicos, espontáneos y provocados, verbales y escritos. Particular relieve ofrecen, desde el punto de vista procedimental, los informes sobre proyectos de disposiciones.

5.11. Nuestro Derecho positivo ofrece base para distinguir entre el órgano que acuerda pedir el informe y el que firma la petición, siquiera nada se diga sobre ello en la LPA.

5.12 La resolución recajda en un procedimiento que haya sido 
objeto de consulta debe comunicarse al organismo emisor del dictamen. Esto no lo dice expresamente la LPA, pero parece que el supuesto puede encajar en el artículo 78, 3), LPA: «Cuando alguna autoridad $\mathrm{u}$ órgano intermedio deba tener conocimiento de la comun1cación, se le enviará copia de la misma», y se prevé expresamente en cuanto a los dictámenes del Consejo de Estado por el Reglamento de 13 de abril de 1945 .

5.13 . No es admisible que el funcionario que emite el informe pueda percibir honorarios profesionales por razón del mismo, ya se trate de informe juridico o de otra clase, siquiera nuestra vigente legislación local permita sostener lo contrario en cuanto a estos últimos.

5.14 No dice con carácter general la LPA cuáles son las consecuencias de la omisión de informes preceptivos, pero es evidente que estaremos ante un caso de anulabilidad por aplicación del artículo 48 LPA, y en este sentido hay que entender modificadas las disposiciones anteriores en que se declaraba vicio de nulidad la omisión de estos informes. A pesar de tratarse de un vicio anulable, no hay posibilidad de convalidación, lo que es lóglco, ya que el informe preceptivo trata precisamente de ilustrar al órgano decisor. 